\title{
Effect of Calcination Temperature on Morphological and Topography of Nickel- Alumina Thin Film
}

\author{
Khairul Ilman Sarwani ${ }^{1,{ }^{*}}$, Rais Hanizam Madon $^{1}$, Siti Aida Ibrahim ${ }^{1}$, and Mas Fawzi ${ }^{1}$ \\ ${ }^{1}$ Energy Technologies Research Group (EnRG),Center for Energy and Industrial Environment \\ Studies (CEIES), Faculty of Mechanical and Manufacturing Engineering, Universiti Tun Hussein \\ Onn Malaysia, 86400 Parit Raja, Batu Pahat, Johor, Malaysia
}

\begin{abstract}
Dip coating process promises good potential of nickel-alumina catalyst deposition on metal substrate for various applications especially in gas conversion reaction. This study was conducted to investigate the effect of different calcination temperature on nickel-alumina catalysts thin film formation. Four different calcination temperature were used, which are $300^{\circ} \mathrm{C}, 400^{\circ} \mathrm{C}, 500^{\circ} \mathrm{C}$ and $600^{\circ} \mathrm{C}$. The calculation process was conducted for a duration of 90 minutes. The deposited thin films were characterized using Atomic Force Microscopy (AFM) and X-ray diffraction (XRD) equipment. The AFM result showed that the surface roughness of the nickel-alumina increase proportionally from 56 to $275 \mathrm{~nm}$ when the calcination temperature increased from 300 to $600^{\circ} \mathrm{C}$. From an observation at high calcination temperature, the atom of grains assisted diffusion at the crystallite point causing grain with lower surface energy become larger. As the calcination temperature increase, the surface profile becomes rough and uneven representing high surface roughness. Thus, the effect of calcination temperature greatly influences the surface roughness of the nickel-alumina thin film.
\end{abstract}

\section{Introduction}

Catalysis is a process to accelerate chemical reaction using a catalyst that is not consumed by the overall reaction. Chemical reaction could be initiate with low amount of energy in presence of catalysts. Currently steam methane reforming has been widely used to produced hydrogen because of its economic feasibility [1]. Among many catalysts available for steam methane reforming, nickel-based catalysts meet these criteria for a whole range of chemical reaction [2]. Moreover, the ability of nickel to absorb large amount of hydrogen help increased the reaction efficiency in the microreactor.

Nickel-based catalyst prepared using sol-gel with alumina support have high hydrogen selectivity. The properties of alumina support are influence by the aluminas treatment temperature [3]. Furthermore, the activity of nickel catalyst supported with alumina made on sol-gel method is influence by the calcination temperature during preparation [4]. Nickel-alumina thin film surface roughness is one of the main potential enhancement factor

\footnotetext{
*Corresponding author: ilmansarwani@gmail.com
} 
for the high methane conversion and hydrogen yield $[4,6]$. It was studied that thin film thickness and roughness is proportional to the substrate's roughness. The formation of the final prepared catalyst depends on the calcination parameter such as time and temperature [6]. An active catalyst is usually finely dispersed metal over support porous alumina. Employed catalyst coated on the plates substrate reduces mass and heat transfer restriction compared with pellet catalyst and can improve its effectiveness for further intensification. The presence of catalyst will lead to faster reaction at certain operating temperature condition, by reducing the amount of energy required to initiate chemical reaction [4]. Furthermore, nickel-alumina prepared by sol gel and dip coating method has been reported to produce more stable support structure and higher nickel dispersion [7]. These dipping process is crucial in determining the properties of coated thin film nickel-alumina catalyst on top of substrate's surface area.

This study aims to observe the effect of calcination temperature on the formation of nickel alumina thin film by dip coating method. Using fixed nickel-alumina sol-gel concentration, various calcination temperatures were tested. By comparing the results obtained from previous literature, it was expected to yield the critical information regarding calcination temperature effects for more optimized nickel-alumina catalyst preparation.

\section{Materials and Methods}

The substrate used are stainless steels grade 304 with a specific dimension of $15 \mathrm{~mm}$ width $\times 60 \mathrm{~mm}$ length $\times 0.5 \mathrm{~mm}$ thickness. Sol-gel solutions were prepared using Nickel(II) nitrate hexahydrate $-\mathrm{Ni}\left(\mathrm{NO}_{3}\right)_{2} \cdot 6 \mathrm{H}_{2} \mathrm{O}$ and Nitric Acid $65 \%-\mathrm{HNO}_{3}$ obtained from R\&M Chemicals, Aluminum isopropoxide - $\mathrm{Al}\left[\mathrm{OCH}\left(\mathrm{CH}_{3}\right)_{2}\right]_{3}$ from Acros Organics, and Ethanol $99.8 \%$ obtained from ChemAR System.

Using Skymen JP-020S ultrasonic cleaner the substrates were cleaned to remove dust and contaminants on the substrate surface. Cleaned stainless steel was polished using abrasive paper. Later, the substrates were sanded with abrasive paper grit 400 to increase it roughness for better adhesion. Each substrate was polished in one way direction for 30 cycles.

The solution was prepared by dissolving $22 \mathrm{~g}$ Aluminum isopropoxide with $5 \mathrm{ml}$ distill water, $5 \mathrm{ml}$ Nitric acid and $90 \mathrm{ml}$ ethanol. Then the solution was stirred at $60^{\circ} \mathrm{C}$ until homogenous for one hour. Next, $10 \mathrm{~g}$ of Nickel (II) nitrate hexahydrate was added slowly the mixture was stirred continuously at $60^{\circ} \mathrm{C}$ until homogenous which took another one hour. The nickel-alumina solution was used directly for dip coating process without undergoing aging process.

The dip coating schematic diagram was shown as Fig. 1. PTL-MM01 Dip Coater was used for dip coating process with dipping and withdrawal speed range of 1-200 $\mathrm{mm} / \mathrm{min}$. For dip coating sector, the dipping and withdrawal speed used was $160 \mathrm{~mm} / \mathrm{min}$. The 304 stainless steel plates were dipped and then withdrawn from the bath at a prescribed withdrawal velocity. For this experiment, the heat treatment used was isothermal annealing by using Carbolite RHF $14 / 3$ box furnace at operating temperature of $300^{\circ} \mathrm{C}, 400^{\circ} \mathrm{C}, 500^{\circ} \mathrm{C}$, $600^{\circ} \mathrm{C}$ for 90 minutes.

In this research, physical tests had been carried out to investigate the characteristic of the deposited thin film catalyst. The substrates were characterized using Atomic Force Microscopy, AFM (XE-100 Park Systems) which provided a 3D profile of the surface in a Nano scale and X-ray diffraction (XRD) to identify unknown crystalline materials on the coated film. The equipment used was Panalytical $\mathrm{X}^{\prime} \mathrm{Pert}^{3}$ Powder and analized using Highscore software. 


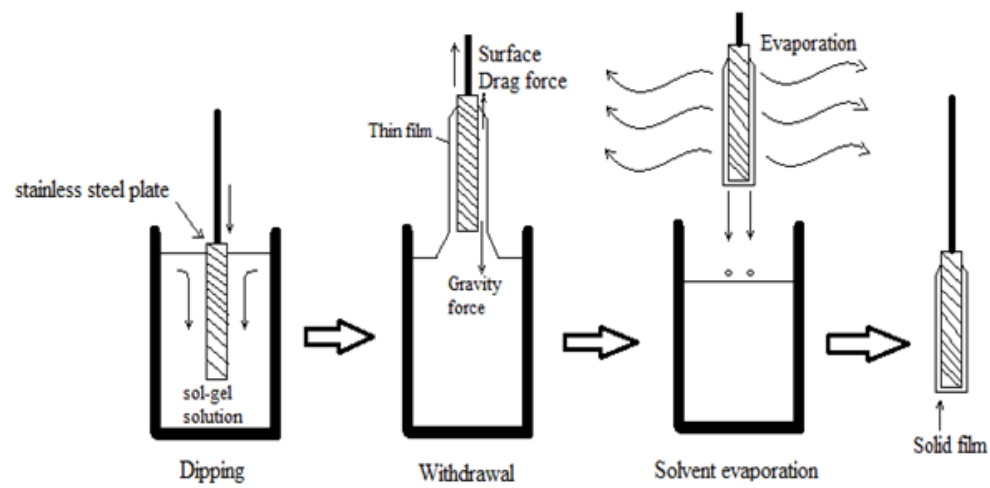

Fig. 1. Schematic diagram of dip coating process.

\section{Results and Discussions}

Fig. 2 shows an AFM image of nickel-alumina thin films calcination from 300 to $600^{\circ} \mathrm{C}$. Based on the result obtained shows the surface of nickel-alumina forming the shape of the hill and valley. According to Kumar et al. [8] as the surface roughness increase, charged oxygen-related species were absorbed on the crystalline film for alumina formation. Due to the high calcination temperatures, there were high potential for the migration of grain's boundaries and straightly causing coalescence of more nickel-alumina grains. The nucleation rate of the particles increased rapidly as the calcination temperature increase causing larger grain. Parra et al. also mentioned when the temperature increase the supersaturation of the reaction products also increase to accelerated the crystal core forming of the reaction within short time [9]. Furthermore, at high temperature stage, the atom of grains is assisting diffusion at the crystallite point to occupy the correct site in the crystal and causing grain with lower surface energy become larger. With temperature continuing to rise, rapid formation of crystal nucleus were expected which control the morphology and structure of the final nickel-alumina film. Crystallite size, particle size and particle morphology are strongly dependent on heating temperature through dip coating, the grain size increase as calcination temperature increase.

Using AFM, the surface roughness was characterize by obtaining the roughness parameters $R_{a}, R_{q}$ and maximum elevation. The surface roughness's of the catalyst prepared play an important role in Steam Methane Reforming (SMR) performance. Measuring the surface roughness of the prepared catalyst is very important to determine hydrogen yield [6]. Fig. 3 represent an analysis of the roughness of each film varying from calcination $300^{\circ} \mathrm{C}-600^{\circ} \mathrm{C}$. At $300^{\circ} \mathrm{C}$ showing only peak without valley represent smooth surface profile indicating low roughness value. Apparently, from $400^{\circ} \mathrm{C}$ to $600^{\circ} \mathrm{C}$ showing more peak and valley represent roughness of the film layer. As the calcination temperature increase the surface profile become more rough and uneven representing high surface roughness. 

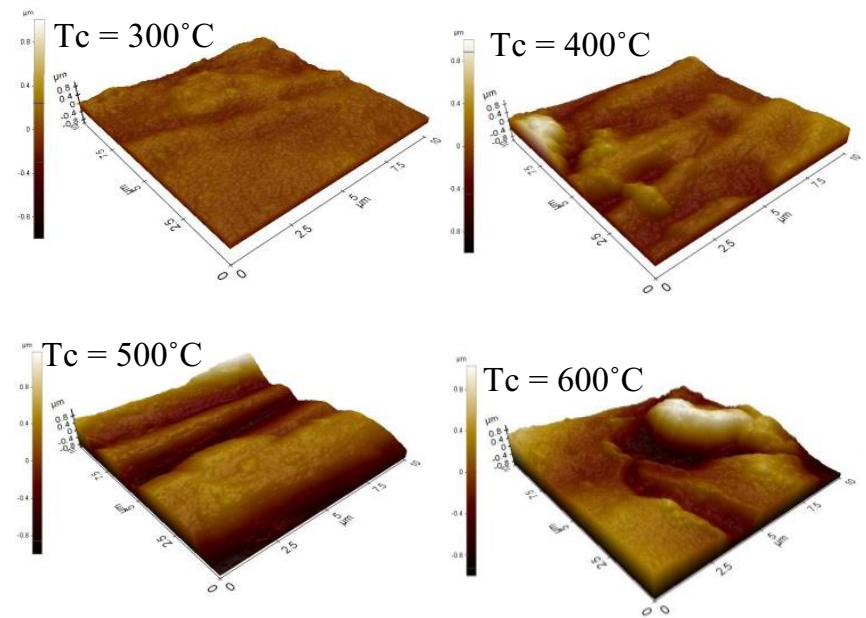

Fig. 2. AFM image of nickel-alumina for calcination temperature.
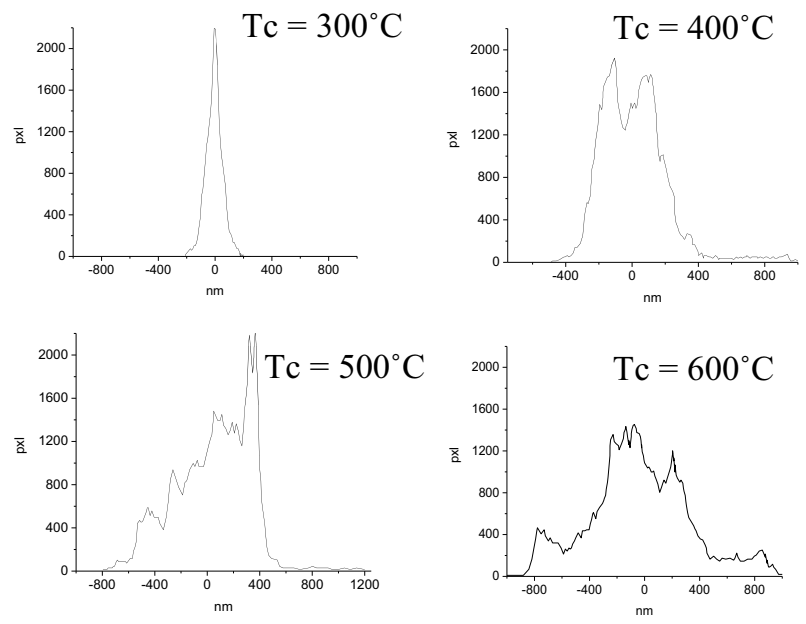

Fig. 3. AFM surface profile analysis of nickel-alumina thin films.

Table 1 shows the average roughness $\left(\mathrm{R}_{\mathrm{a}}\right)$ had the same trend as the ten-point mean height $\left(R_{z}\right)$ for all prepared nickel alumina thin film. Surface roughness of the nickelalumina increase from 56 to $275 \mathrm{~nm}$ as the calcination temperature increased from 300 to $600{ }^{\circ} \mathrm{C}$. From Table-1 shows high value $\mathrm{R}_{\mathrm{a}}, \mathrm{R}_{\mathrm{z}}$ also has high value because of strong dependence of $R_{z}$ on the peak height or valley depth. From Gaussian distribution of asperity height show that the ratio $\mathrm{R}_{\mathrm{q}}$ to $\mathrm{R}_{\mathrm{a}}$ should be 1.25 [8]. As shown in Table-1, the maximum value of $\mathrm{R}_{\mathrm{q}} / \mathrm{R}_{\mathrm{a}}$ is 1.32 , which reasonably closed to the value of 1.25 indicating the statistical relationships for surface roughness are applicable. In Table 1, negative value of skewness $\left(\mathrm{R}_{\mathrm{sk}}\right)$ indicate that the valleys are dominant over scanned area and positive values show that the peaks are dominant on the surface. In this case, the negative value indicates crack on the film layer. The defect caused by the adatoms trapped at these sites forming nuclei for subsequent growth process called heterogeneous nucleation. The nuclei will then grow due to further addition of adatoms and the island up to that size can dissolve again as stated by Bäumer et al. Since the values were low, the cracks were minor [8]. 
Table 1 also showing the value of $R_{\mathrm{ku}}$ had more than 3 indicating high peaks and low valley due to strong relation between $R_{z}$ and $R_{a}$.

Table 1. Roughness parameters of nickel-alumina thin films annealed at different temperatures.

\begin{tabular}{|c|c|c|c|c|c|c|}
\hline $\begin{array}{c}\text { Calcination } \\
\text { Temperature }\left({ }^{\circ} \mathbf{C}\right)\end{array}$ & $\begin{array}{c}\mathbf{R}_{\mathbf{a}} \\
\mathbf{n m}\end{array}$ & $\begin{array}{c}\mathbf{R}_{\mathbf{q}} \\
\mathbf{n m}\end{array}$ & $\begin{array}{c}\mathbf{R}_{\mathbf{z}} \\
\mathbf{n m}\end{array}$ & $\mathbf{R}_{\mathbf{q}} / \mathbf{R}_{\mathbf{a}}$ & $\mathbf{R}_{\text {sk }}$ & $\mathbf{R}_{\text {ku }}$ \\
\hline 300 & 56 & 74 & 581 & 1.314645 & -0.006 & 3.746 \\
\hline 400 & 134 & 177 & 1322 & 1.320427 & -1.288 & 6.564 \\
\hline 500 & 244 & 302 & 2007 & 1.237705 & 0.123 & 3.275 \\
\hline 600 & 275 & 355 & 1898 & 1.290909 & -0.213 & 3.132 \\
\hline
\end{tabular}

Based on Table 1 the average roughness $(\mathrm{Ra})$ and ten-point height $(\mathrm{Rz})$ were plotted into graph as shown in Fig. 4. The value Rz also coFuld be used as the thicknesses of the thin film since it calculate the difference between highest peak and lowest valley. Rz values in Fig. 4 showed as the calcination temperature increase the thickness of the thin films also increase. The highest thickness obtained is at temperature $500^{\circ} \mathrm{C}$, the thickness drop at $600^{\circ} \mathrm{C}$. It was the evident that the particles become flatter when the adhesion energy increases. Apparently, the value of surface roughness did not affected by thickness of the thin film as shown in Fig. 4 , the surface roughness of the thin film still increasing even at $600^{\circ} \mathrm{C}$.

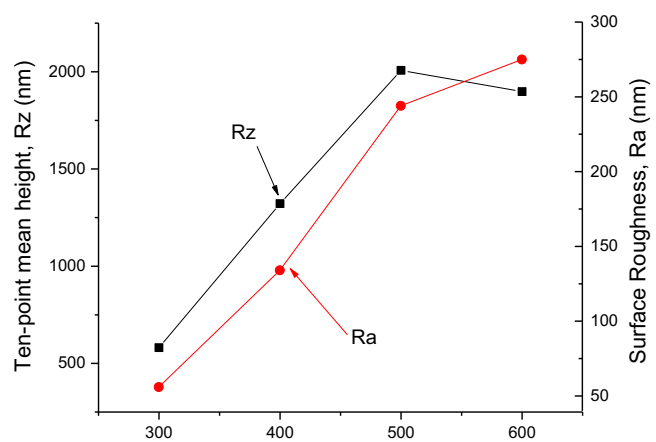

Fig. 4. Thin film surface roughness (Ra) and ten-point mean height $(\mathrm{Rz})$ measured using AFM.

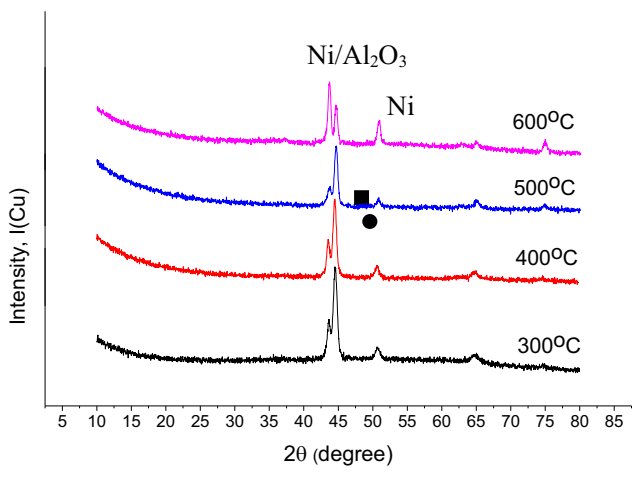

Fig. 5. XRD patterns of catalyst calcined at various temperature

All calcined catalysts were examined by XRD in order to investigate the phase development. Fig. 5 present similar pattern for catalysts calcined at $300,400^{\circ} \mathrm{C}, 500^{\circ} \mathrm{C}$ and $600^{\circ} \mathrm{C}$. It appeared that there is not much changein particle size with calcination temperature. It can be seen that Nickel phase and nickel - alumina phase were presents on the substrates. As the temperature increase the amount of nickel decreasing to form nickel alumina. This may indicates that temperature play an important role for the formation of nickel - alumina. 


\section{Conclusions}

This study had shown that the surface roughness of the nickel-alumina increase proportionally from 56 to $275 \mathrm{~nm}$ as the calcination temperature increased from 300 to 600 ${ }^{\circ} \mathrm{C}$. In addition, the calcination temperature would stimulate the migration of grain's boundaries and straightly causing coalescence of more grains. As observe from the surface profile, it has become more rough and uneven which representing high surface roughness accordingly to the increment of calcination temperature. The XRD result also shown that as the calcination temperature increase the formation of nickel alumina would greatly become higher. Therefore, a high temperature during the catalyst preparation is expected to increase the yield of the steam methane reforming process.

The author would like to thank the Ministry of Education for partly supporting this research under the Fundamental Research Grant Scheme (FRGS) vot. 1421.

\section{References}

1. Y. Bang, S. Park, S.J. Han, J. Yoo, J.H. Song, J.H. Choi, K.H. Kang, and I.K. Song, Appl. Catal. B-Environ., 180, 179 (2016)

2. A. Ishihara, T. Imai, T. Hashimoto, H. Nasu, Fuel Process. Technol., 136, 34 (2015)

3. Z. Yaakob, A. Bshish, A. Ebshish, S.M. Tasirin, F.H. Alhasan, Materials, 6(6), 2229 (2013)

4. B. Bej, N.C. Pradhan, S. Neogi, Catal. Today, 207, 28 (2013)

5. S. Allahyari, M. Haghighi, A. Ebadi, Chem. Eng. Process. Process Intensif, 86, 53 (2014)

6. A.S.A. Al-Fatesh, A.H. Fakeeha, Journal of Saudi Chemical Society, 16(1), 55 (2012)

7. M. Zangouei, A.Z. Moghaddam, M. Arasteh, Chem. Eng. Res., 14(2), 97 (2010)

8. B. Rajesh Kumar, T. Subba Rao, Dig. J. Nanomater. Bios. 7(4), 1881 (2012)

9. M.R. Parra, F.Z. Haque, J. Mater. Res. 3(4), 363 (2014) 